\title{
Policy Implementation of Improving Education Quality of Primary Education Teachers in Laos and Indonesia
}

\author{
Viengdavong Luangsithideth ${ }^{1}$, Muhammad Huda ${ }^{1}$, Ahmad Supriyanto ${ }^{1} \&$ Bambang B. Wiyono $^{1}$ \\ ${ }^{1}$ Post Graduate Program, State University of Malang, Indonesia \\ Correspondence: Viengdavong Luangsithideth, Post Graduate Program, State University of Malang, Indonesia. \\ E-mail: Viengdavong Luangsithideth: puiv10705@yahoo.co.id; Muhammad Huda: muh_huda47@yahoo.com; \\ Ahmad Supriyanto: aspriess@gmail.com; Bambang B. Wiyono: bambudi2007@yahoo.com
}

Received: January 22, 2017

doi:10.5539/ass.v13n3p145
Accepted: February 3, $2017 \quad$ Online Published: February 15, 2017

URL: http://dx.doi.org/10.5539/ass.v13n3p145

\begin{abstract}
The purpose of this research is to get deep meaning of policy implementation to improve quality of primary education teachers in Laos and Indonesia. Research locations are in the Ministry of Education in those both countries. This research used a qualitative approach with a multi-case study design. First, policy formulation consider the aspect of novelty and national education goals; second, policy dissemination of existing policies do after getting approval from parliament, as well as socialization is done to the department of education in each provinces and districts; third, policy implementation process is done by establishing a monitoring team to oversee that the policy can work well; fourth, monitoring and evaluation of the implementation is done periodically, at least every six months, and the results of the evaluation are reported to the Ministry; fifth, gaps in the policy implementation is because monitoring can not be run with maximum caused by geographical conditions and the weakness of the role of school supervisors; sixth, efforts to repair gaps in the implementation of policies to improve the quality primary school teachers is to make laws on the teacher, as well as to provide training to teachers and principals.
\end{abstract}

Keywords: policy implementation, education quality, teacher quality

\section{Introduction}

Education is the key word in any effort to improve the quality of human life within which it has a role and objective to 'humanize'. Education is essentially the process of maturation quality of life. Through the process of human expected to understand the meaning and essence of life, and for what and how to carry out the task of living and life correctly. That's why the focus of education is directed to the formation of a superior personality with emphasis on the quality of the maturation process of logic, heart, character, and faith. The highlight was reaching the point of perfection education quality of life.

Thus, to get a good quality education, the governments of Laos, particularly the Ministry of Education and Sport (MoES) Laos began to notice the importance of improving the quality of Human Resources (HR) through the strengthening of education, especially in the field of education basic, and more specific is regarding quality of the teachers.

When compared with the State of Indonesia, it is interesting that in Indonesia there is Law No. 20 of 2003 about National Education System, in particular in article 51, mentioned that "Management Unit of Early Childhood Education, Primary Education and Secondary Education, implemented by minimum service standards and the principles of the School Based Management/ Madrasah ", while in Laos is there is no education law yet which quite clear, so that the education system in Laos is still not quite strong.

Furthermore, with regard to the implementation of the education policy in Indonesia then Sa'ud (2002) suggested that the decentralization of education management showed the delegation of authority in education management from the central government to the autonomous regions, which puts the district/city as the center of decentralization. The shift in power is closely related to the concentration of policy formulation and decision-making. That is, the authority granted to the lower hierarchy of policy formulation and decision-making is an important feature of decentralization. As well as Ben-Peretz (2009) argues that it is basically a policy analysis that uses the application of social science to explain the reasoning and evidence, assess and solve the 
problems concerning the wider community.

Some previous relevant studies, such as by UNESCO (1995 and 2011); UNICEF (2011); and UNDP (2014) suggested that one quality of education resulting in an educational institution is of the quality of teachers. Especially for the quality of teachers in primary schools need to be shaded by law in order to produce good academic understanding for students before moving on to secondary education. Against this then in a state needs to be a policy-relevant and measurable in order to improve the quality of teachers in the primary schools.

\section{Method}

Focus of this research are: a) the formulation of policies improving the quality of primary school teachers by the Ministry of Education; b) socializing Elementary School Teacher Quality improvement by the Ministry of Education; c) policy implementation process quality improvement Elementary School Teachers; d) monitoring and evaluation of the implementation of policies to improve the quality of Primary School Teachers; e) gaps in the implementation of policies to improve the quality Primary School Teachers; and f) efforts to fix gaps in the implementation of policies improving the quality of Primary School Teachers.

The research was conducted over eleven months in two Ministry of Education in Laos and Indonesia. This research is multi-case study of qualitative research which design using the comparative constant method with the steps: (1) data collection from the Department of Pre-School Education and Basic Education, Ministry of Education and Sports (MOES) Laos; (2) continued data collection from the Directorate General of Teacher and Education Personnel, Ministry of Education and Culture, Indonesia.

Based on the sixth of this research focus on the ministry of education in Laos and Indonesia, then researchers conducted a comparative study to find the meaning of improving the quality of education of primary school teachers in order to improve the quality of basic education.

Given this study using a multi-case study design, then in analyzing the data is done by analyzing the data of individual cases and data analysis across cases, (Creswell, 2010). First, relate with analyzing the data of individual cases, the data analysis was performed on the individual case the Ministry of Education and Sports in Laos, as well as the Ministry of Education and Culture. in Indonesia, namely with regard to the legislation in force in the field of education, especially in primary education. In the analyzes, the researchers conducted the interpretation of the data in the form of words, in order to obtain the meaning. Because the analysis carried out together with the data collection process, as well as the data collected.

Second, relate with analyzing the across cases. Cross-case data analysis is intended as the process of comparing the findings obtained from each case, as well as the process of integrating between cases. Given this study is between the two institutions the Ministry of Education in the two countries, namely Laos and Indonesia, then the fisrt step by researcher is on the findings of the case at the Department of Primary School, Ministry of Education and Sports, Laos, which continued to the Directorate of Elementary Schools, Ministry of Education and Culture of the Republic of Indonesia. Based on this, further findings of the case that there are arranged categories and themes, analyzed inductively conceptual and narrative explanations made arranged in a certain proportion, and then developed into a substantive theory.

The proportions of the substantive theory I (case finding in the Ministry of Education and Sports, Laos) then analyzed by comparing the proportions and substantive theory II (case finding in the Ministry of Education and Culture, Indonesia) to find the differences in the characteristics of each case as based on different theoretical conceptions. The difference in both cases is made while the findings were then analyzed simultaneously to reconstruct and develop conception of equality cases I and II systematically. Furthermore, cross-case analysis between I and II with the same technique. The final analysis is intended to draw up a systematic conception based on data analysis and theoretical interpretation of the narrative form of the proportions of cross-case which is then used as a material for developing the theory of substantive findings.

The measures undertaken in the analysis across these cases include: (1) using an inductive approach by comparing and combining the findings conceptual of each individual case, (2) results are used as a basis for preparing the statement of conceptual or proportions of cross cases, (3) evaluate the suitability of proportion with the fact that the reference, (4) reconstruct the proportions correspond with the facts of each individual case, and (5) use this process as appropriate, to the limit of saturation.

\section{Findings}

First, the formulation of policies improving the quality of primary school teachers by the Ministry of Education and Sports in Laos is to consider in six aspects, such as: 1) results from international agencies that partner with the government; 2) the ability of human resources in Laos who are knowledgeable about educational 
management; 3) geographical conditions for the distribution of teachers; 4) quality and quantity of higher education teacher; 5) educational background of the teachers; and 6) ability of education funding. Whereas in Indonesia which conducted by the Minsitry of Education and Culture is to consider in eight aspects, such as: 1) national development goals in education; 2) the results of the strategic plan produced by the Ministry of Education; 3) the results of the strategic plan that is in each of the provinces and districts; 4) the results of the study of international agencies that partner with the government; 5) geographical conditions for the distribution of teachers; 6) the quality and quantity of higher education teacher; 7) the educational background of the teachers; and 8 ) the ability of education funding.

Second, improving the quality of policy dissemination Elementary School Teacher by the Ministry of Education and Sports, Laos have steps are gradual socialization, such as: (1) the information by letter from the ministry of education to all the departments of education in the province; (2) conduct training to all staff in the education department in the province that is responsible for the field in accordance with the basic policy of activities issued by the Ministry of Education; (3) from the province provide notification to the district, as well as to all school districts in each area of the new policy of the ministry; (4) provincial staff who have received training from the Ministry of Education, responsible for providing training to the staff in the district; and (5) the staff of the district to provide training to principals and teachers that are relevant to the subject of the policies issued by the ministry of education. The result of all these activities further reported to the Ministry of Education to find gaps in the field and in the framework of the improvement in the future. However, the whole process would require a budget, and for budgeting issues still have to come from the government and the ruling party. Whereas in Indonesia which conducted by the Minsitry of Education and Culture is to consider in five aspects, such as: (1) collect all the provincial education department head of the ministry of education policy; (2) upload policies which have been authorized by the government to be read in the web in general; (3) socialization in the area carried out by each province; (4) of the policies relating to technical problems, the teacher quality improvement in every province involving education quality assurance agency, as an arm of the central government in the province; (5) for implementation in each area of the district education offices provide socialization to all principals and school supervisors.

Third, implementation of the policy of increasing the quality of elementary school teachers in Laos is to consider five aspects, namely: (1) mobilization of human resources at the provincial and district level to oversee government policy; (2) funding from the government; (3) a clear regulatory support; (4) empowering school supervisor; and (5) parents and community awareness about the importance of mentoring children in the family as an effort of parental support for education of children in the house. Whereas in Indonesia is to consider in six aspects, such as: (1) empowerment of education quality assurance agencies at the provincial level as a technical representative bodies of the Ministry of Education who were in every province; (2) empowers the board of education in every province; (3) encourage the provincial government to issue local regulations regarding the implementation of the policy of the Ministry of Education; (4) The budget allocation is appropriate and relevant from the government; (5) the deployment of human resources at the provincial and district level to oversee government policy; and (6) empower school committee as part of community involvement in supporting the advancement of education in schools.

Fourth, monitoring and evaluation of policies to improve the quality of primary school teachers in Laos can be interpreted in four ways, such as: (1) that the monitoring and evaluation carried out in an integrated manner between institutions at the Ministry of Education and Sports, Laos is between the Department of Inspection, Department of Teacher Training, until to the provincial, district, and school; (2) that the monitoring is done to ensure that the policies issued by the central government can be implemented up in the area; (3) that the existing monitoring and evaluation was conducted to determine the gap between the real condition of the field with the expected conditions in accordance with the policy; and (4) that the monitoring and evaluation to support primary school teachers in meningatkan professional capacity to be able to teach well. Whereas in Indonesia is to consider in five aspects, such as: (1) monitoring of the level of the school is the school's obligation to make the school self-evaluation document at the end of each school year submitted to the district education office; (2) monitoring at the district level is done by the provincial education department which in this case is in the field of education quality assurance authority; (3) monitoring at the provincial level undertaken by the Ministry of education in this regard in the directorate general authority of teachers and education personnel; (4) the monitoring process at the district always involves the role of school inspectors; and (5) program of the Ministry of Education on teacher performance assessment conducted each year and shall be followed by all teachers.

Fifth, gaps in the implementation of policies to improve the quality of primary school teachers in Laos can look at two aspects. The first aspect is the internal ministry of education, namely with regard to: (1) limited human 
resources who understand true about management education and public policy; (2) regarding the budget allocation for education, especially for teachers; (3) regarding the equitable distribution of teachers from urban to in remote areas; and (4) with respect to the accuracy of the monthly salary of teachers who should have been received on time. The second aspect is the school itself, which is related to: (1) the lack of support from parents to children the importance of education, including the school's needs; (2) a lack of children's learning materials such as books and other educational tools that support learning; (3) still adanyanya multigrade teachers, this is due to a shortage of teachers; (4) the willingness of teachers to learn more professional, it can be observed from the weakness of the teachers in preparing lesson plans; and (5) health and hygiene of children who come from homes are still many who do not clean in a condition that disrupts the learning atmosphere. Whereas in Indonesia is to consider in five aspects, such as: (1) the existence of graduate teacher but did not want to be a teacher; (2) the existence of laws in Indonesia which suggests that teachers should have an undergraduate qualification; (3) many teachers prefer to teach in schools that have access kemudahahan transportation than that placed in the interior; (4) the role of the board of education and school superintendent is not maximized.

Sixth; efforts to improve the quality gap elementary school teacher in Laos is to consider seven aspects, such as: 1) with the cooperation between the government and foreign institutions engaged in the field of education to examine together the reality of conditions in the field based on existing reports; 2) formulate relevant policies based on the results of scrutiny in the field and document reports of each of the Department of Education in each province; 3 ) the bond provides scholarships to students who are completing studies at the college that will be placed as a primary school teacher in areas that are short-staffed; 4) provide training to principals and school supervisors with regard to educational leadership and understanding of learning strategies in the classroom by teachers; 5) the Ministry of Education and Sports (MOES) to optimize the human resources that are relevant for routine monitoring visits spaciousness; 6) Government needs to pay attention to the timeliness of teachers' salaries on a monthly basis; and 7) the need for a recruitment system memadahi school superintendent that the school superintendent can portray his responsibility. Whereas in Indonesia is to consider in five aspects, such as: (1) optimize the role of the teacher union republic of Indonesia; (2) the award to the outstanding teachers; (3) the existence of such a program of undergraduate teaching in remote areas, teaching Indonesia, Indonesia intelligent front-line teachers, is a distribution program for young teachers stricken remote areas to fill the shortage of teachers and for learning innovation together with local teachers; (4) promoting educational development planning from the village up to the provincial level; (5) the bond provides scholarships to students who are completing studies at the college that will be placed as a primary school teacher in areas that are short-staffed; (6) training programs and teacher certification in order to support the improvement of teaching quality; and (7) an increase in the role of quality of supervision by the school principal.

\section{Results and Discussions}

\subsection{Formulation of Policies Improving the Quality of Primary School Teachers}

Fowler (2004) mentioned that the development of education should be planned carefully and precisely by those who understand the art so as to bring out a policy of strategic and measurable. Based on the statement, as well as the conditions in the two countries, Laos and Indonesia, it can be interpreted that the formulation of educational policy needs to consider several things such as: (1) The geographic aspect of justice; (2) aspects of the needs of the school or district; (3) the funding aspect; and (4) the aspect of global competition.

First, with regard to the geographical aspects of justice. Based on the two countries have a geographical distribution almost the same, where many schools are located in areas that are difficult affordability then justice considerations geography can be interpreted that the education policies issued by the government could consider, such as: (1) the relevance of the policy with conditions in the region; (2) the impact of the policy; and (3) monitoring and continuity of policies. It is important that the planned policy relevant and can cover conditions in a region to equality and the advancement of national education. It is as stated by Kaufman (1979) that the planning of education in a country must consider the condition dinaunginya region, so that the existing policy can have an impact on equity for the region.

Second, aspects of the needs of schools or regions. It is more the role of teachers' needs in the learning process, such as books, educational products, and curricula that are relevant to local conditions. Based on these three things then existing policy formulation can provide space to schools in the region in monitoring local education office to be able to plan the educational needs with proportionate and relevant. It also points out Rizvi \& Lingard (2009), as well as Hermino (2013) that the assessment of educational need expressed directly from the region would help the central government in monitoring the condition of education as a whole, so that planning policies generated can lead to partiality relevant. 
Third, the funding aspect. It is concerned with the education of equity financing needs and budget allocation by the central government in accordance with the conditions of each area. It also points out Fowler (2004) and Mason (2013) that the financing aspect is a crucial aspect of improving the quality of education in a country, where the proportion and relevance of the financing will affect the spirit of teachers in teaching. The statement can be interpreted also that the strategic policy planning in the field of education budgeting needs to consider: (1) the economic conditions of the school environment; (2) the need for teachers in the learning process; and (3) learning targets in accordance with the demands of the curriculum. The third condition is also aligned such as set by the Kaufman (1979) that one of the efforts to improve the quality of teachers in schools is with the fulfillment of the relevant funding to the schools in order to achieve a better quality of education.

Fourth, aspects of globalization. It is concerned with the development of the current era where modernization and globalization requires the fulfillment of a good quality education. In this regard, the policy planning education in a country should also consider the progress of time in order to compete in the global competition (World Bank, 2011). Under these conditions, the policy planning in order to improve the quality of teachers, especially in primary schools need to consider: (1) the background of teacher education; (2) the qualifications and competence of teachers; (3) the real challenges faced by teachers in school; (4) the relevance of the curriculum to local conditions; and (5) regulation of local support to the presence of the teacher. Fifth it would support the government in planning regulations and relevant policies and clear. This condition as stated also by Munadi \& Barnawi (2011) that the formulation of the national education policy should be able to integrate the relevance of regional needs with the demands of global competition, where the two should complement each other and that is why the role of the existing policy needs to consider siding with the teacher as the motor of progress education.

Overall the above description is also in line as proposed by Alisyahbana (2000) in Munadi \& Bernawi (2011: 19) that public policy education can be defined as a decision taken jointly by the government and actors outside the government and consider the factors that influence to be implemented or not implemented at the field of education that includes education budget, curriculum, recruitment of staff, professional development of staff, land and building, resource management, and other policies that directly or indirectly berentuhan education.

\subsection{Socializing Elementary School Teacher Quality improvement by the Ministry of Education}

Socializing in conducting quality improvement Elementary School Teacher by the Ministry of Education needs to pay attention to three aspects, namely: (1) dissemination strategy; (2) the impact of socialization; and (3) follow-up of the results of socialization. It is also like addressed Fowler (2004) and Loomis, et al (2008) that the socialization of a policy program is not just to inform but also to consider the strategy and the sustainability of the results of socialization.

First, dissemination strategy. Socialization strategies need to consider such as: (1) the time is right for the socialization process both at the center and in the provinces and in the region; (2) the right person to provide socialization, that is understood about the policy that is being socialized, and in particular the understanding of the duties of teachers in their responsibility for improving the quality of education; (3) ways to socialize, whether to use the lecture method, brochure or use of relevant technology media; (4) funding for socialization, whether borne by the central government or provincial governments sharing together; (5) ensure that the process of socialization that can be precisely targeted to teachers, and teachers can be ensured to understand the meaning of socialization. Against this it also points out Lewis (1983); Peng et al (2013) that the strategy of socialization of a government policy to be right on target and on time, and using the relevant resources in the delivery of socialization, it is intended that the delivery of strategic programs that can be heard and understood by all parties concerned.

Second, the impact of socialization. Target of socialization are primary school teachers, and thus the expected impact also is to improve the quality of teaching and the quality of the results of the students during the learning process. Against this, the relevant impact of socialization can be observed from the start if: (1) the socialization process using the right people and understand the material being disseminated; (2) the attendees were the right people, both from the teacher and which represents teachers in the right capacity anyway; and (3) allow for election of strategic issues that come directly from the field, which can potentially strengthen the policy of the central government. This condition is also as stated in Fowler (2004) that the impact of socialization is the expected outcome of the process of socialization itself, so that the policy implementation process can run well.

Third, follow-up of the results of socialization. It is as stated in Glewwe (2014) that the socialization process that works is when followed by the right and the result was an impact on the smooth running of government policy during the run. Against this, the follow-up of socialization expected are: (1) a good understanding of the teacher 
as the direct recipient of the policy; (2) to improve the quality of teacher performance; and (3) an increase in the quality of learning outcomes of students.

\subsection{Policy Implementation Process Quality Improvement Elementary School Teachers}

The process of improving the quality of policy implementation Elementary School Teacher needs to consider: (1) the qualifications and competence of teachers; (2) old teachers teach; (3) the geographical conditions of the schools where teachers teach; and (4) the demands of the national curriculum in order to achieve the national goals of education.

First, with regard to the qualifications and competence of teachers, it is in order to be with the policies adopted by the government, teachers can improve the qualifications and competence, both in the methods of teaching and student achievement results achieved. However, as noted in Hermino (2014) that the principal's role is crucial in scrutinizing the ability of every teacher in the school in order to improve the quality of learning. Based on these conditions, the implementation of policies to improve the quality of teachers can work well if there is engagement and good leadership from the school principals.

Second, experiences of teacher teaches. It is intended that the implementation of the policy does not make the teacher to be confused with the experiences that have been obtained previously. Furthermore, too, that the new policy is expected to be able to support teachers to improve their knowledge and innovation in the learning process does. Hanson (2003) and Skaalvik \& Skaalvik (2013) suggests that the combination between the experience of teachers teaching with the policies issued by the school or the government will be able to improve the competence of teachers in teaching. Observing this, it can be interpreted that the implementation of policies to improve the quality of teachers will be able to run properly if the direct beneficiaries that teachers can understand them properly in accordance with local conditions and the school where the teacher teaches.

Third, the geographical condition of the school where the teacher teaches. An implementation of the policy will be targeted and successful if attention to the geographical and social conditions of the local (Fowler, 2004). Based on these statements, it can be interpreted that efforts to improve the quality of primary school teachers in each region is different of course, but these differences can be a force for the development of national education system in a country where in the policy planning attention and consider the geographical aspects of justice. Geographical Justice here means that the central government leaving room for teachers both in urban and remote areas to develop creativity and innovation in teaching methods, but remained within the umbrella of the policies imposed by the government. It is also as stated by Reinhartz \& Beach (2004); Peng et, al (2013) that the policy issued by the government is still providing space and opportunities for teachers to be creative and to increase its capacity but remains within the guidelines of national policy.

Fourth, the demands of the national curriculum. It is better to order the implementation of national policies can lead to national development goals set by the government, while the national curriculum is as a means to achieve the goal of national education (Hamalik, 2010). With regard dengann these conditions, the implementation of policies to improve the quality of teachers is also necessary synergy with the national curriculum itself. Similarly, the central government with the resources that exist for the socialization of the policy also provides an understanding of the national curriculum imposed. Furthermore, also in its implementation still required the assistance to the teachers so that the teachers' creativity and innovation space can still be developed in line with the national curriculum enacted and national goals of education is to be achieved.

4.4 Monitoring and Evaluation of the Implementation of Policies to Improve the Quality of Primary School Teachers

Monitoring and evaluation of the implementation of policies to improve the quality of Primary Teachers need to consider several things such as: (1) indicators in monitoring and evaluation; (2) the time and the process of monitoring and evaluation; and (3) follow-up of monitoring and evaluation. It also points out Fowler (2004) that the monitoring and evaluation of a policy will be able to show the level of success of the policy.

First, with regard to indicators in monitoring and evaluation. It is as stated also in Fowler (2004) that the determination of the indicators in a monitoring and evaluation process will be easier for the government in monitoring the success rate including the constraints and barriers during the implementation process runs. Observing this, the indicators in monitoring and evaluation is relevant to the government's competence expected of teachers in order to implement the policy. The indicators of teacher competence that was also to be informed of the national government to the teachers so that every teacher without exception knowing what things are become government policy.

Second, the time and the process of monitoring and evaluation. It is intended that the monitoring process is going 
well according to the scheduled time. Given the schedule, the school can prepare and prepare time well too. Against the monitoring process is carried out based on the indicators that have been set by the government and which has also been previously socialized. However, for the implementation of the time and process monitoring by both the provincial and central governments can work well, the process of monitoring and evaluation on a regular basis can be done by school inspectors, who also acts as a supervisor at the elementary schools. It also points out Owen (1995) and Rodriguez (2014) that the superintendent of schools should serve not only as a school superintendent, but also perform the function of management in the form of supervision to target schools that are responsible so that the national policy set by the government may also running well.

Third, the follow-up of monitoring and evaluation. During the process of monitoring and evaluation will certainly obtain the things achieved and not achieved, or what works and does not work, according to the indicators that have been set with regard to efforts to improve the quality of teachers. Based on real data from the field can be mapped out next government: (1) schools where the teacher has not been reached maximal competence; (2) what things are still to be given to teachers in order to achieve competency standards expected by the government; and (3) gab is happening in the field that should be achieved as a target of the government. It also points out Hermino (2013) that their school mapping will allow the central government in monitoring the implementation of policies that are being implemented.

Overall the above statement is also in line as proposed in Fowler (2004: 13) that The policy process is the sequence of events that occurs when a political system considers different approaches to public problems, adopts one of them, tries it out, and evaluates it.

\subsection{Gaps in the Implementation of Policies to Improve the Quality Primary School Teachers}

Gaps in implementation of the policy of improving the quality of Primary School Teachers. It aims to determine the conditions that occur in the field with the expected conditions, including the root problems that arise with regard to efforts to improve the quality of teachers (Glewwe, 2014). Based on these statements, it can be interpreted that the gab that occur in the field will help the government in such things as: (1) obtain the latest achievements of the quality of existing teachers; (2) the constraints and obstacles during the process of policy implementation; (3) the root of the problem so the present of the gab; and (4) mapping the roots of the problem based on the location of the school, the needs of schools and teacher competence. Further to achieve the intended fourth thing then there are two things that need to look like: (1) indicators set by the authorities with regard to the competence and qualification of teachers to be achieved must be relevant and measurable; and (2) the necessity of harmony between the implementation of the national curriculum with efforts to improve teacher quality to be achieved.

The condition also as suggested by Ben-Peretz (2009); Mason (2013) also confirmed that by the policy-relevant education and firmly in a country, then the country will have a direction education programs is also clear, and will further strengthen the development of strategic plan for education that is relevant to the need for States as well as with respect to the global competition in education today.

Referring to all of the above three things regarding the gaps in the implementation of policies to improve the quality of primary school teachers, then there are three variables or factors that influence the emergence of these gaps, namely: a) Policy variables. Which included policy variable is the clarity of the policy objectives, the transmission (policy delivery). Unclear objectives and policy delivery to the implementor cause a difference in perception. This condition will complicate the process of policy implementation will be; b) Variable or organizational factors. One public policy should be implemented through an instrument or tool as well as a specific vehicle, in short there is no public policy without associated with a particular device. Instruments for implementing public policy in the context of the state administration dilasanakan through organizations or public organizations. Organizations that meant the author is not an organizational structure but rather on personnel (the implementing agency); and c) Implementation environment variables or factors. One of the policies implemented by the organization or group of organizations do not occur in a vacuum, but implementation has occurred in a particular environment. Implementation environment can be shaped condition of public education, social conditions under which the policy was implemented and political conditions.

Overall statement above is also in line with that proposed by Tilaar (2009); Marshall \& Gerstl-Pepin (2005); and Ben-Peretz (2009) that if the policy carried out in two different environments will give different results, so the application of the policy must pay attention to the policy environment in which this policy is implemented. Similarly affirmed by Rizvi and Lingard (2009); and Jones (2013) that the other difficulties that hinder the implementation of the policy, may also be influenced by the orientation or interest officials or heads of local governments to the existing policy. Many issues that must be done, priority choice what policies will be 
implemented depending on the interest and the orientation of regional leaders.

\subsection{Efforts to Fix Gaps in the Implementation of Policies Improving the Quality of Primary School Teachers}

There are some constructive efforts in order to improve policy implementation gaps on improving the quality of primary school teachers, such as: (1) the existence of a working group of teachers; (2) working group principals; (3) the core school and school impact; (4) empowering the board of education in the region; (5) empower the school committee; (6) empowering the role of supervisor of the school; (7) political education budget in favor of improving the quality of education; and (8) the annual national discussion education as the central government steps to capture the aspirations of the regions and the central government in an effort to propose national policies in education is to be achieved. This condition is also as stated in Fowler (2004); Loomis et,al (2008); Mason (2013) that need to be real and strategic efforts in addressing the disparities that occur during the process of implementation of the policy subuah, for the target to be achieved can be managed properly.

First, the working group of teachers. This working group can do in their respective schools on a monthly basis or in accordance with the needs of the school, led by principal who acts as a supervisor. The teachers working group talks about things that annoy experienced by teachers during the teaching process, or the difficulties faced by the teacher. The presence of the teacher working group will greatly assist teachers in monitoring the root of his problems during the teaching process, as well as a space for teachers to share their experiences in order together to improve the competence of teachers in the school. It is also as stated by Mulyasa (2011) that the professional group of teachers at the school were done regularly will increase the capacity of the role of school principals and teachers to jointly promote the existing education at the school.

Second, the working group principals. It is an effort to ensure the competence of principals in schools that are adjacent to or within a cluster can share their experiences, both in terms of leadership and management aspects of the school. The working group's principals led directly by the school superintendent as the supervisor of schools that became auxiliaries. It also points out Mulyasa (2011) that the capacity of school leadership can be enhanced by the holding group of principals.

Third, the core school and school-induced. The core school is a school with the capacity and competence of teachers who fulfills the adequacy of the indicators set by the government, while the spillover schools are schools around the core school is still in one cluster, which still requires improving the quality of existing teachers. Their school and school-induced core is based on the mapping carried out by the government and based on the analysis of gab obtained during the evaluation process and monitoring in the field. It is also as stated by Rival \& Pure (2009) that the education management will be able to walk properly in accordance with the national policy of education in a country where their school mapping in a comprehensive manner, and informing their schools can be used as a core school or school example, which aims to provide a positive impact on surrounding schools were still not up to quality.

Fourth, empowering the board of education in the area. It is intended that their shared responsibility in the region to jointly pay attention to education and the quality of teachers in schools in the area. Board of education can be interpreted as a local government partners in an attempt sense of belonging to the existence of schools in the area, as well as mutual concerned about the welfare of teachers in the area. Board of education can function also as the 'home' for teachers to be able to express their aspirations against the constraints and barriers experienced when the school and the school committee was not able to solve existing problems. However, the existence of the board of education can be a strategic partner governments in an effort to assist the process of implementing policies in the area (Fowler, 2004).

Fifth, empowering the role of the school committee. Mulyasa (2011) argued that the existence of the school committee can help smooth the process of education in a school, and their presence can also help the government in implementing a government policy. Meanwhile, with regard to improving the quality of teachers, then Glewwe (2014); Mason (2013); Rodriguez (2014) suggested that their involvement in school committees giving insufficient attention to the needs of schools will help teachers to improve the quality of learning in schools. Referring to this, the necessary regulations to overarching presence school committee, and it is also necessary to build the capacity of the school committee's role in helping to improve the quality of teachers in schools. As examples of relevant training is such an understanding of education in the family, because of the presence of these, the responsibility of the education of children is not just handed over only to the schools, but in society and the family, the education of children remains a common concern. With the synergy of the attention it will be easier for teachers to continue to pursue the achievement of better learning.

Sixth, the empowering role of school supervisors. The school superintendent are professionals who understand the field of education, and its existence is a representative of the local education office to provide supervision to 
help schools become surrogate in order to improve the quality of education (Hanson, 2003). Observing the statement, the appointment of school supervisors based on: (1) the competence and qualifications, not on seniority or rank or age; (2) academic eligibility demonstrated academic achievement; and (3) the practical feasibility of commitment shown by the work program to be carried out.

Seventh, political education budget in favor of improving the quality of education. Politics budget in question is with regard to teacher salaries that are relevant and can be received on time. Relevance salary teachers need to be shaded by law so that there is transparency, as well as taking into account the geographical fairness in schools where teachers teach. Fowler (2004) asserts that political education budget should be based on national goals of education is to be achieved and based also on the conditions of each area. Under these conditions, with budgeting education, especially for teachers' salaries in the amount of relevant and timely unacceptable then this will be the motivating teachers to be able to work well and constantly improving his professional capacity as a teacher.

Eighth, the annual national discussion education as the central government steps to capture the aspirations of the regions and the central government in an effort to propose national policies in education is to be achieved. It is intended that the central government can directly meet with education officials in each area as well as hear directly aspirations emerging from the region, which have not been recorded during the process of monitoring and evaluation in these areas. In addition to the national discussion of education can also be used as a means of reaffirming the central government's national education policy direction and strategies implemented to achieve the objectives of the national education (Djokopranoto, 2011).

\section{Conclusion}

Based on the overall description above, can be summarized as follows: (1) education policy will be relevant when extracted from the root of the problem and needs assessment in the area; (2) The policy of improving the quality of teachers could be relevant if the government has a clear school mapping and relevant, both from the existence of the school, the deployment of teachers, teacher qualifications, and competence of teachers; (3) the indicators are relevant in assessing teacher performance will allow the government to find the gab that occur in order to improve the quality of teachers; (4) empowering the role of superintendent of schools in the area will greatly assist in efforts to oversee the implementation of policies promulgated by the government; (5) pengalokasiaan salary budgets that are relevant to the teacher as well as the timeliness of teachers receiving salaries would motivate teachers to be able to work as an educator with the better; (6) national discussion education is a means for the central government to listen to the aspirations of the region with respect to improving the quality of teachers, as well as government facilities are also in reaffirming the program and strategy of implementing existing policies.

Furthermore, the results of this study presented suggestions to: (1) the education department in the province in order to optimize the role of a school supervisor in order to supervise the schools and teachers in order to improve their competence and professional capacity as an educator. Further also that supervisors supervisinya ekolah always communicate the results to the local education department as a school mapping of the condition of education in the region; (2) the Ministry of Education in Laos and Indonesia, in order to increase the quality of teachers dikonkritkan policies in the domain of school-based management with level indicators to be achieved;

(3) for educational management experts and researchers in order to examine the implementation of relevant policies to improve the quality of teachers not only of the level of process alone but on the level of the root problems that occur in the field, so that the policy issued will be relevant and on target for improving the quality of education.

\section{Acknowledgments}

A fellowship provided for the Southeast Asian Studies Regional Exchange Program (SEASREP) is gratefully acknowledged. The results of this research will certainly contribute to the development of quality basic education in Laos. The author thanks to: (1) Prof. Dr. H. Muhamad Huda, M.Pd for assistance and comments that greatly improved the manuscript; (2) Dr. H. Ahmad Supriyanto, M.Pd., M.Si, for sharing his time and positive insight; (3) Prof. Dr. H. Bambang Budi Wiyono, M.Pd for the unwavering guidance; (4) for the unwavering moral support of the proponents' family and friends; and also special support from Mr. Lytou Bouapao Deputy Minister, Ministry of Education and Sports (MoES) Laos, and Dr. James Modouw from Ministry of Education and Culture (MoEC), Indonesia.

\section{References}

Ben-Peretz, M. (2009). Policy Making in Education. A Holistic Approach in Response to Global Changes. New 
York: R\&L Education Publisher.

Creswell. (2010). Research Design: Qualitative Approach, Quantitative, and Mixed Design. Jogyakarta: Pustaka Pelajar.

Djokopranoto, R. (2011). Education Philosophy in Indonesia. The Series of Essays Education Problems. Jakarta: Obor

Fowler, F. C. (2004). Policy Studies For Educational Leaders. An Introduction (2nd ed.). Ohio: Pearson Merrill Prentice Hall

Glewwe, P. (2014). Education Policy in Developing Countries. Chicago: The Universiry of Chicago Press.

Hamalik, O. (2010). Manajement of Curricculum Development. Bandung: Remaja Rosdakarya

Hanson, E. M. (2003). Educational Administration and Orgaizational Behavior (5th ed.). Boston: Pearson Education, Inc.

Hermino, A. (2013). Need Assessment for Schooling Organization. Jakarta: Gramedia Pustaka Utama Publisher, Inc.

Hermino, A. (2014). Education Leadership in the Globalization Era. Yogyakarta: Pustaka Pelajar, Inc.

Huda, A. Y. (2010). Study of Regional Autonomy Philosophy of Education Filosofi. Malang: Fakulty of Educational Science. State University of Malang. Indonesia.

Jones, T. (2013). Understanding Education Policy. Armidale, New South Wales: School of Education, University of New England.

Kaufman, R. A. (1979). Educational System Planning. New Jersey : Prentice Hall Inc., Engleewood Cliffs.

Lewis, J. Jr. (1983). Long-Range and Short-Range Planning for Educational Administrators. Massachusetts: Allyn and Bacon, Inc.

Loomis, S., Rodriguez, J., \& Tillman, R. (2008). Developing Into Similarity: Global Teacher Education in The Twenty-First Century. European Journal of Teacher Education, 31(3), 233-245.

Marshall, C., \& dan Gerstl-Pepin, C. (2005). Re-Framing Educational Politics for Social Justice. Boston: Pearson Education, Inc.

Mason, M. (2013). Educational inequality and educational quality. International Journal of Educational Development, (34) 1-2.

Mulyasa, H. E. (2011). Manajemen Kepemimpinan Kepala Sekolah. Jakarta: Bumi Aksara

Munadi, M., \& Barnawi. (2011). Public Policy in Education. Joyjakarta: Ar-Ruzz Media

Owens, R. G. (1995). Organizational Behavior in Education. Boston: Allyn and Bacon.

Peng, W. J., McNess, E., Thomas, S., Wu, X. R., Zhang, C., Li, J. Z., \& Tian, H. S. (2013). Emerging Perceptions of Teacher Quality and Teacher Development in China. International Journal of Educational Development, (34), 58-66.

Reinhartz, J., \& Beach, D. M. (2004). Education Leadership. Changing Schools, Changing Roles. Boston: Pearson Education, Inc

Rivai, V. H., \& Murni, S. (2009). Education Management. Anaysis of Theory and Practices. Jakarta: Rajawali Pers.

Rizvi, F., \& Lingard, B. (2009). Globalizing Education Policy. New York: Routledge.

Rodriguez, F. (2014). A Community College District Chancellor's View on Transformational Leadership. Journal of Transformative Leadership and Policy Studies, 4(1).

Sa'ud, U. S. (2002). Development of Education Policy in the Framework of Regional Autonomy. Retrieved from http://file.upi.edu/Direktori/FIP/JUR._ADMINISTRASI_PENDIDIKAN/195306121981031-UDIN_SYAE FUDIN_SA'UD/Kebijakan_Pend.-Bapenas_2002.pdf.

Skaalvik, E. M., \& Skaalvik, S. (2013). Teachers' Perceptions of The School Goal Structure: Relations with Teachers' Goal Orientations, Work Engagement, and Job Satisfaction. International Journal of Educational Development, (62), 199-209.

Tilaar, H. A. R. (2009). Power and Education. National Education Management In the Whirl Power. Jakarta: Rineka Cipta. 
United Nations Children's Fund (UNICEF). (2011). Child Friendly Schools. Case Study: Lao People’s Democratic Republic. Vientiane: UNICEF.

United Nations Educational, Scientific and Cultural Organization (UNESCO). (1995). Education Policy-Planning Process: An Applied Framework. Paris: United Nations.

United Nations Educational, Scientific and Cultural Organization (UNESCO). (2011). World Data on Education. Lao PDR. VII Ed. 2010/2011. Accessed on 10 March 2015. http://www.ibe.unesco.org/)

United Nation Development Program. (UNDP). (2014). Progress Report on the Millennium Development Goals in Indonesia. Retrieved from http://www.undp.or.id/pubs/imdg2014/bi/indonesiamdg_bi_goal2.pdf.

World Bank. (2011). Learning for All. Investing in People's Knowledge and Skills to Promote Development. World Bank Group Education Strategy 2020. Washington: The World Bank.

\section{Copyrights}

Copyright for this article is retained by the author(s), with first publication rights granted to the journal.

This is an open-access article distributed under the terms and conditions of the Creative Commons Attribution license (http://creativecommons.org/licenses/by/4.0/). 